\title{
Analytical solution of velocity distribution for flow through submerged large deflection flexible vegetation*
}

\author{
Wei-jie WANG ${ }^{1}$, Wen-xin HUAI ${ }^{1}$, Yu-hong ZENG ${ }^{1}$, \\ Ji-fu ZHOU ${ }^{2}$
}

(1. State Key Laboratory of Water Resources and Hydropower Engineering Science, Wuhan University, Wuhan 430072, P. R. China;

2. Institute of Mechanics, Chinese Academy of Sciences, Beijing 100192, P. R. China)

\begin{abstract}
An analytical solution for predicting the vertical distribution of streamwise mean velocity in an open channel flow with submerged flexible vegetation is proposed when large bending occurs. The flow regime is separated into two horizontal layers: a vegetation layer and a free water layer. In the vegetation layer, a mechanical analysis for the flexible vegetation is conducted, and an approximately linear relationship between the drag force of bending vegetation and the streamwise mean flow velocity is observed in the case of large deflection, which differes significantly from the case of rigid upright vegetation. Based on the theoretical analysis, a linear streamwise drag force-mean flow velocity expression in the momentum equation is derived, and an analytical solution is obtained. For the free water layer, a new expression is presented, replacing the traditional logarithmic velocity distribution, to obtain a zero velocity gradient at the water surface. Finally, the analytical predictions are compared with published experimental data, and the good agreement demonstrates that this model is effective for the open channel flow through the large deflection flexible vegetation.
\end{abstract}

Key words analytical velocity distribution, linear drag force, flexible vegetation, large deflection, mixing length theory

Chinese Library Classification TV133.1

2010 Mathematics Subject Classification $\quad$ 76F99

\section{Nomenclature}

$A, \quad$ effective bulk drag coefficient;

$A_{\mathrm{f}}, \quad$ frontal area of the stem;

$A_{\mathrm{s}}, \quad$ surface area of the stem;

$A_{L}$, projected area of the element on the coordinate plane $O x y$;

$C_{i}, \quad(i=1,2, \cdots, 4)$ integration coefficient;

$C_{\mathrm{d}}, \quad$ form drag coefficient;
$C_{\mathrm{f}}, \quad$ friction drag coefficient;

$C_{\mathrm{L}}, \quad$ lift coefficient;

$C_{\mathrm{p}}$, perimeter of the stem cross-section;

$C_{\mathrm{v}}$, dimensionless coefficient in the drag force formula;

$D$, frontal-projected width of the stem;

$D_{1}$, length of the major axis for ellipse;

* Received Dec. 13, 2013 / Revised Jun. 19, 2014

Project supported by the National Natural Science Foundation of China (Nos.11372232 and 51479007), the Specialized Research Fund for the Doctoral Program of Higher Education (No. 20130141110016), and the State Water Pollution Control and Management of Major Special Science and Technology (No. 2012ZX07205-005-03)

Corresponding author Wen-xin HUAI, Professor, Ph. D., E-mail: wxhuai@whu.edu.cn 


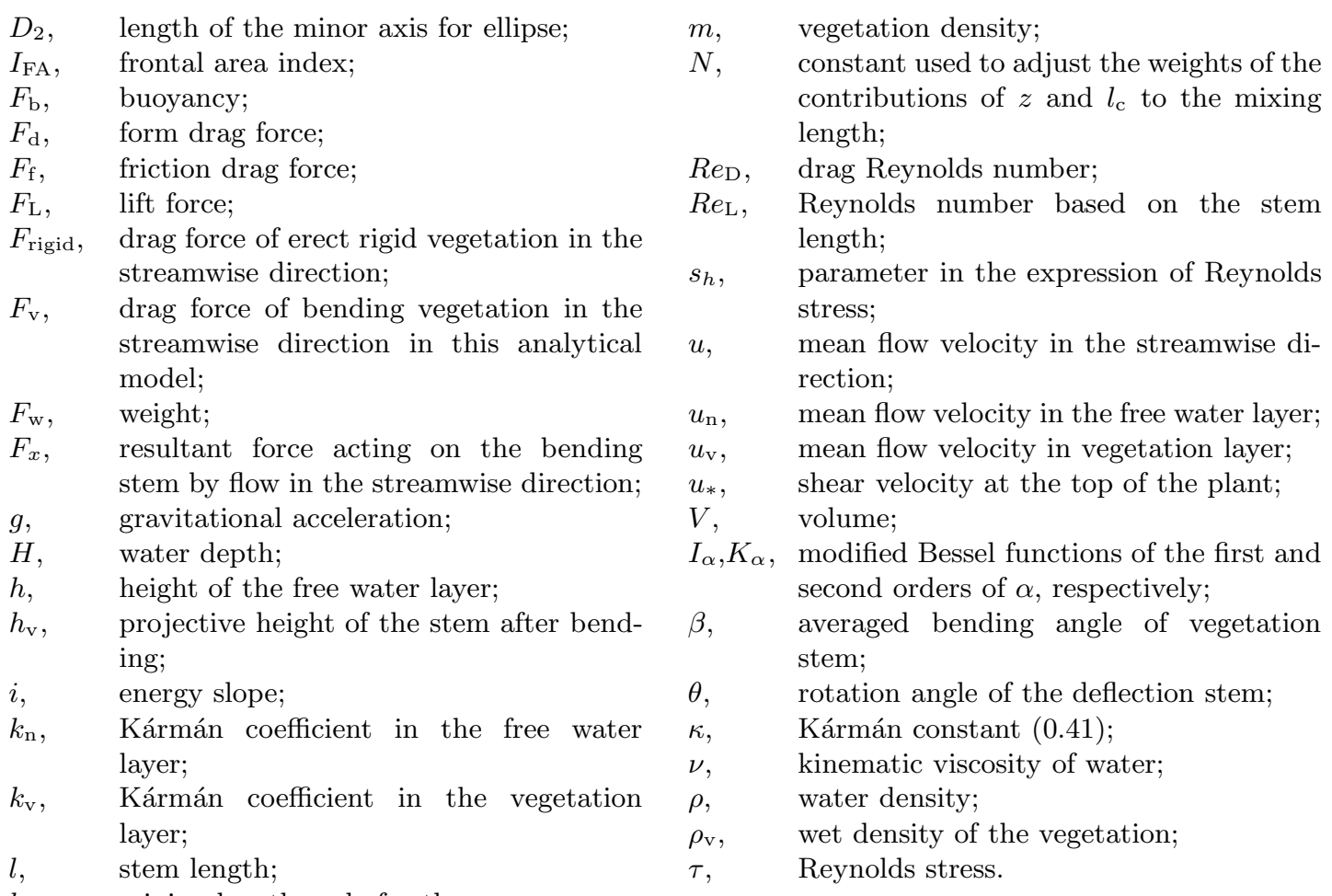

\section{Introduction}

The hydrodynamic characteristics of flow in open channels with aquatic vegetation have been widely studied. Vegetation in open channels alters the structure of the water flow, increases flow resistance, affects the transport of sediments and solutes, and has a significant impact on the environment ${ }^{[1-3]}$.

Many types of aquatic vegetation are flexible, easy to bend, and have a form that is streamlined in flowing water ${ }^{[4]}$. Recent studies have examined the characteristics of flexible aquatic vegetation, which differ from those of rigid aquatic vegetation ${ }^{[3,5-6]}$. The bending of flexible vegetation in flowing water is an important characteristic related to hydraulic and vegetation properties ${ }^{[4,7-9]}$. In contrast to rigid erect vegetation, for which the drag force-velocity variation shows a squared relationship ${ }^{[10]}$, flexible plants are bent into a streamlined form with increasing flow velocity, resulting in significantly reduced drag ${ }^{[1-12]}$. Besides the drag reduction in water flow, this drag reduction phenomenon was also observed in air flow ${ }^{[13-15]}$.

The linear relationship between the drag force and the flow velocity was observed in various experiments. For example, Armanini et al. ${ }^{[16]}$ measured the resistance of willows in a prototype experiment using a designed force transducer. Their results showed that the stiffness of the vegetation played an important role in the vegetation drag. For partially submerged rigid willows, the drag force-velocity variation showed the traditional square relationship. For completely submerged flexible vegetation, a linear drag force-velocity variation was observed, which can be explained by the streamlined form of the trees which results in decrease in the momentumabsorbing area. Wilson et al. ${ }^{[17]}$ conducted a laboratory research on this relationships of 22 full-scale trees of three different genera $(1.4 \mathrm{~m}-4 \mathrm{~m})$. They found that for the full-scale trees, the drag force tends to vary linearly with velocity when it is over $0.5 \mathrm{~m} / \mathrm{s}$, while for lower velocities $(0 \mathrm{~m} / \mathrm{s}-0.5 \mathrm{~m} / \mathrm{s})$, the drag force-velocity variation maintains the squared relationship. This linear drag force-velocity relationship was also observed in the experiments of Schoneboom et 
al. ${ }^{[18]}$ with artificial poplars.

Various studies focused on the resistance of vegetation (or use cylinders to simulate vegetation $)^{[19-21]}$. For example, Wang ${ }^{[22]}$ investigated the flow characteristics of flow around a square cylinder by the large eddy simulation (LES). The velocity distribution can reflect the characteristics of vegetation resistance on flows, which have been studied by different methods for the rigid vegetation ${ }^{[2,23-25]}$. For example, Liu et al. ${ }^{[26]}$ proposed analytical models of streamwise velocity in flows with submerged shrub-like vegetation. Yang et al. ${ }^{[27]}$ experimentally studied the velocity distribution of flows in different types of vegetations such as arbors, shrubs, and grass. For the channel partially covered with vegetation, Zhang et al. ${ }^{[28]}$ developed the $2 \mathrm{D} k-\epsilon$ turbulence hydrodynamic model to simulate the turbulent vegetated flow in this situation.

For the flow through flexible vegetation, the effect of vegetation bending on the turbulent flow structure should be taken into consideration. Huai et al. ${ }^{[9]}$ proposed an analytical velocity model when the bending of vegetation is not too large. However, for large bending of flexible vegetation, the simulation of the bending curve by the analytical model adopted by Huai et al. ${ }^{[9]}$ (Eq. (11) in that paper) may not reflect the real situation, because the hypothesis of the uniformly distributed total load on the vegetation stem to calculate the bending curve may have a large deviation from the actual situation. In this case, we try to propose a new analytical solution for the large deflection in the vegetated flow. In this paper, we conduct a mechanical analysis on flexible plants to verify the linear vegetation drag force-velocity relationship, which was observed in experiments by other researchers. Then, we propose a new drag force-velocity expression, which is a new attempt to describe the vegetation drag when large deflection occurs, and formulate the corresponding momentum equations for each layer to obtain the analytical solution of the velocity distribution in the open channel flow through flexible vegetation with large deflection.

\section{Theoretical analysis}

\subsection{Deflection of flexible vegetation}

In a uniform, steady, and fully developed turbulent open channel vegetated flow, flexible vegetation bends under the forces exerted by the flowing water. Take a flexible cylinder stem (see Fig. 1) to conduct mechanical analysis. $\theta$ is the rotation angle of the deflection stem, and $h_{\mathrm{v}}$ is the projective height of the stem after bending. Figure 1 illustrates five forces acting on a small element $\mathrm{d} s$ : the element weight $\mathrm{d} F_{\mathrm{w}}$, the element buoyancy $\mathrm{d} F_{\mathrm{b}}$, the lift force $\mathrm{d} F_{\mathrm{L}}$, and two kinds of drag force: the form drag force $\mathrm{d} F_{\mathrm{d}}$, which is normal to the stem, and the friction drag force $\mathrm{d} F_{\mathrm{f}}$, which acts along the stem.

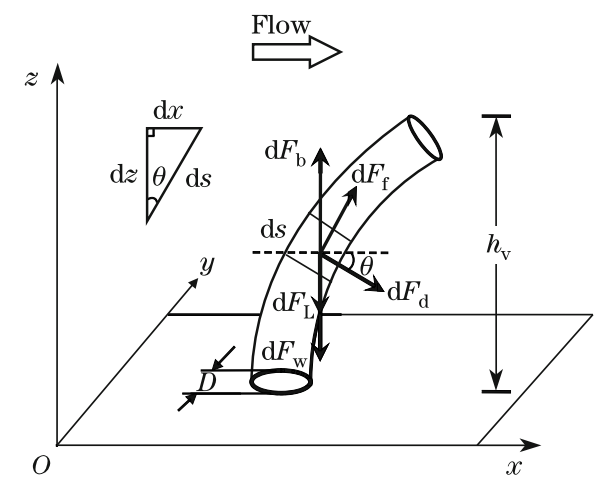

Fig. 1 Schematic of forces on single-stem flexible plant with significant bending

The weight of the element can be calculated by its volume and density, which can be ex- 
pressed as

$$
\mathrm{d} F_{\mathrm{w}}=\rho_{\mathrm{v}} g \mathrm{~d} V
$$

where $\rho_{\mathrm{v}}$ is the wet density of the vegetation, $g$ is gravitational acceleration, and $\mathrm{d} V$ is the volume of the element.

The submerged flexible vegetation is subjected to an upward buoyancy force in the flow, which can be expressed as

$$
\mathrm{d} F_{\mathrm{b}}=\rho g \mathrm{~d} V
$$

where $\rho$ is the water density.

When the flow moves through the bending vegetation stem, it generates a lift force, which is perpendicular to the streamwise direction. The lift force is downward ${ }^{[4]}$ when $0<\theta<\pi / 2$ and can be expressed as

$$
\mathrm{d} F_{\mathrm{L}}=\frac{1}{2} C_{\mathrm{L}} \rho u^{2} \mathrm{~d} A_{\mathrm{L}},
$$

where $C_{\mathrm{L}}$ is the lift coefficient, $\mathrm{d} A_{\mathrm{L}}$ is the projected area of the element on the coordinate plane $O x y$, and $u$ is the mean flow velocity in the streamwise $(x)$ direction. It is noted that the flow velocity in this paper refers to the mean velocity rather than the instantaneous flow velocity.

The form drag force normal to the stem and the friction drag force along the stem can be calculated by ${ }^{[7,29]}$

$$
\begin{aligned}
& \mathrm{d} F_{\mathrm{d}}=\frac{1}{2} C_{\mathrm{d}} \rho(u \cos \theta)^{2} A_{\mathrm{f}}=\frac{1}{2} C_{\mathrm{d}} \rho(u \cos \theta)^{2} D \mathrm{~d} s, \\
& \mathrm{~d} F_{\mathrm{f}}=\frac{1}{2} C_{\mathrm{f}} \rho(u \sin \theta)^{2} A_{\mathrm{s}}=\frac{1}{2} C_{\mathrm{f}} \rho(u \sin \theta)^{2} C_{\mathrm{p}} \mathrm{d} s,
\end{aligned}
$$

where $C_{\mathrm{d}}$ is the form drag coefficient, $C_{\mathrm{f}}$ is the friction drag coefficient, $A_{\mathrm{f}}$ is the frontal area of the stem, $A_{\mathrm{s}}$ is the surface area of the stem, $D$ is the frontal-projected width of the stem, and $C_{\mathrm{p}}$ is the perimeter of the stem cross-section. The geometric relationship gives

$$
\mathrm{d} s=\frac{\mathrm{d} z}{\cos \theta} .
$$

The resultant force acting on the bending stem by flowing water in the streamwise direction can be calculated by the projecting buoyancy, the lift force, the form drag force, and the friction drag force in the streamwise direction (since weight is not the interaction force between flow and vegetation, it is not included here). It can be seen that only the form drag force and the friction drag force work in the flow direction, while the other two forces are perpendicular to the flow direction. Therefore, the resultant force $F_{x}$ acting on the bending stem by flowing water in the streamwise direction is

$$
\mathrm{d} F_{x}=\mathrm{d} F_{\mathrm{d}} \cos \theta+\mathrm{d} F_{\mathrm{f}} \sin \theta .
$$

The drag force of bending vegetation acting on the flowing water can also be expressed as Eq. (7), because the acting force and the reacting force are equal and opposite (Newton's third law of motion).

Substituting Eqs. (4), (5), and (6) into Eq. (7) gives

$$
\frac{\mathrm{d} F_{x}}{\mathrm{~d} z}=\frac{1}{2} \rho u^{2}\left(C_{\mathrm{d}} D \cos ^{2} \theta+C_{\mathrm{f}} C_{\mathrm{p}} \frac{\sin ^{3} \theta}{\cos \theta}\right) .
$$


As an example, in the experiments of Kubrak et al. ${ }^{[30]}$, the cylindrical stems with an elliptical cross-section (the length of the major axis $D_{1}=0.00095 \mathrm{~m}$, the minor axis $D_{2}=0.0007 \mathrm{~m}$, and the stem length $=0.165 \mathrm{~m}$ ) were used to simulate flexible plants in a glass-walled flume. $D=0.00095 \mathrm{~m}$ and $C_{\mathrm{p}}=0.0026067 \mathrm{~m}$ based on the elliptical cross-section.

The form drag and friction drag coefficients vary with the flow velocity and the vegetation characteristics. The form drag coefficient is determined as suggested by Schlichting ${ }^{[31]}$,

$$
C_{\mathrm{d}}=\left\{\begin{array}{l}
3.07 R e_{\mathrm{D}}^{-0.168}, \quad R e_{\mathrm{D}}<800, \\
1.0, \quad 800 \leqslant R e_{\mathrm{D}}<8000 \\
1.2, \quad 8000 \leqslant R e_{\mathrm{D}}<10^{5}
\end{array}\right.
$$

where $R e_{\mathrm{D}}$ denotes the drag Reynolds number, which can be calculated as

$$
R e_{\mathrm{D}}=\frac{u D \cos \theta}{\nu}
$$

The friction drag coefficient in a turbulent flow is calculated by ${ }^{[32]}$

$$
C_{\mathrm{f}}=\frac{0.074}{R e_{\mathrm{L}}^{0.2}},
$$

where $R e_{\mathrm{L}}$ denotes the Reynolds number based on the stem length

$$
R e_{\mathrm{L}}=\frac{u l}{\nu}
$$

where the stem length $l=0.165 \mathrm{~m}$ in the experiments of Kubrak et al. ${ }^{[30]}$, and $\nu$ is the kinematic viscosity of water. Substituting the form drag coefficient $C_{\mathrm{d}}$ and the friction drag coefficient $C_{\mathrm{f}}$ into Eq. (8) gives the relationship between the streamwise drag force and the mean velocity, as shown in Fig. 2. Different types of lines indicate different bending angles.

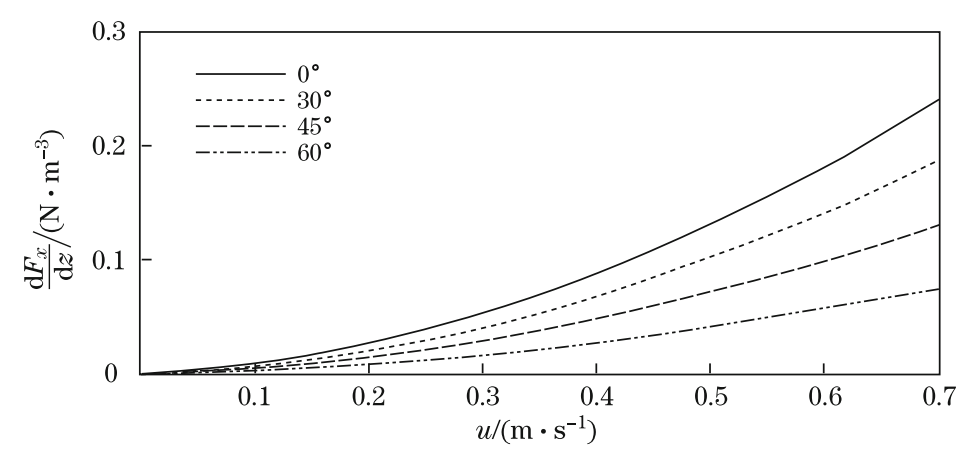

Fig. 2 Relationship between streamwise drag force and mean velocity

The streamwise drag force-velocity relationship (see Fig. 2) becomes almost linear with the increasing bending angles. According to the experimental results of Kubrak et al. ${ }^{[30]}$, the velocity in the vegetation layer is less than $0.7 \mathrm{~m} / \mathrm{s}$. Therefore, we set the velocity range in this figure to $0 \mathrm{~m} / \mathrm{s}-0.7 \mathrm{~m} / \mathrm{s}$. For the larger bending angles, the force-velocity relationship may be substituted by straight lines with different slopes. Wilson et al. ${ }^{[1]}$ suggested that the linear relationship occurred when the velocity was over $0.5 \mathrm{~m} / \mathrm{s}$ for full-scale trees of three different genera. It is reasonable to assume that a linear force-velocity relationship occurs over a certain range of flow velocity for certain types of vegetation since the flexibility of different types of 
vegetation is different. However, the velocity may not necessarily be the factor, which directly determines whether the drag-velocity relationship is linear. The bending angle may be the decisive factor, as shown in the theoretical results in Fig. 2, where the relationship appears linear with increasing bending angles. In fact, the bending angle of flexible stems varies with the bending curve and is not always a constant. Generally, the drag force-velocity relationship can be approximately regarded as linear when large bending occurs ${ }^{[16-18]}$.

\subsection{Model construction}

For the uniform, steady, and fully developed turbulent open channel flow through flexible vegetation, the flow regime is separated into two horizontal layers: a vegetation layer and a free water layer, as shown in Fig. 3. $H$ is the water depth, $h=H-h_{\mathrm{v}}$ denotes the height of the free water layer, and $\beta$ is defined as the averaged bending angle, which is the angle between the vertical direction and the line through the initial and final points of bending.

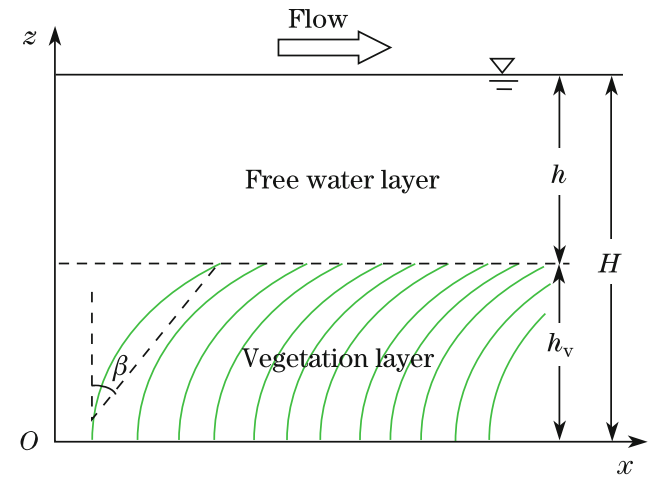

Fig. 3 Open channel flow with submerged flexible vegetation

\subsubsection{Flow in vegetation layer}

In the vegetation layer, considering the force balance between the Reynolds shear stress, the gravity component, and the drag force of the vegetation, the momentum equation can be expressed as

$$
\frac{\partial \tau}{\partial z}-\frac{\partial F_{\mathrm{v}}}{\partial z}+\rho g i=0
$$

where $\tau$ is the Reynolds stress, $F_{\mathrm{v}}$ is the vegetation drag force in the streamwise direction, and $i$ is the energy slope.

For the Reynolds stress, a first-order closure scheme is presented

$$
\tau=\rho k_{\mathrm{v}} u_{*} z \frac{\partial u_{\mathrm{v}}}{\partial z}
$$

where $k_{\mathrm{v}}$ is defined as the Kármán coefficient in the vegetation layer, $u_{*}=(g i h)^{1 / 2}$ is the shear velocity at the top of the plant, and $u_{\mathrm{v}}$ is defined as the flow velocity in the vegetation layer.

The vegetation drag force for an erect rigid plant is ${ }^{[10]}$

$$
\frac{\partial F_{\text {rigid }}}{\partial z}=0.5 \rho C_{\mathrm{d}} m D u_{\mathrm{v}}^{2}
$$

where $m$ is the vegetation density, which is defined as the number of stems per unit bed area. When large bending occurs, we approximate the drag force-velocity relationship as linear. Similar to the form of Eq. (15) for rigid vegetation, the drag force of flexible vegetation is 
presented below. Here, we introduce the shear velocity $u_{*}$ as a characteristic velocity to balance the dimensions in the equation

$$
\frac{\partial F_{\mathrm{v}}}{\partial z}=\rho C_{\mathrm{v}} m D u_{*} u_{\mathrm{v}}
$$

where $F_{\mathrm{v}}$ is the drag force of the bending vegetation in the flow direction, and $C_{\mathrm{v}}$ is a dimensionless coefficient which is similar to the coefficient $0.5 C_{\mathrm{d}}$ in Eq. (15).

Substituting Eqs. (14) and (16) into Eq. (13) gives

$$
\frac{\partial}{\partial z}\left(k_{\mathrm{v}} u_{*} z \frac{\partial u_{\mathrm{v}}}{\partial z}\right)-\left(C_{\mathrm{v}} m D u_{*}\right) u_{\mathrm{v}}+g i=0 .
$$

The flow velocity in the vegetation layer can be obtained from the above equation

$$
u_{\mathrm{v}}(z)=C_{1} I_{\alpha}(f(z))+C_{2} K_{\alpha}(f(z))+\frac{g i}{C_{\mathrm{v}} m D u_{*}}
$$

where $C_{1}$ and $C_{2}$ are the integration coefficients, and $I_{\alpha}$ and $K_{\alpha}(\alpha=0$ and 1$)$ are the modified Bessel functions of the first- and second-order of $\alpha$, respectively.

The vertical gradient of the flow velocity is

$$
\frac{\partial u_{\mathrm{v}}(z)}{\partial z}=\frac{f(z)}{2 z}\left(C_{1} I_{1}(f(z))-C_{2} K_{1}(f(z))\right)
$$

where

$$
\begin{aligned}
& f(z)=2 \sqrt{A \frac{z}{h_{\mathrm{v}}}}, \\
& A=\frac{C_{\mathrm{v}}}{k_{\mathrm{v}}} m D h_{\mathrm{v}} .
\end{aligned}
$$

Here, the frontal area index $I_{\mathrm{FA}}=m D h_{\mathrm{v}}$, which is the total frontal area of the vegetation elements per unit area of the bed. Then, Eq. (21) can be expressed as

$$
A=\frac{C_{\mathrm{v}}}{k_{\mathrm{v}}} I_{\mathrm{FA}}
$$

This equation shows that the frontal area index times a coefficient $C_{\mathrm{v}} / k_{\mathrm{v}}$ equals the parameter $A$. Therefore, the parameter $A$ indicates the effect bulk drag coefficient of bending vegetation in the vegetation layer $h_{\mathrm{v}}$. It is known that flexible stems bend in flowing water, and the height of vegetation layer is compressed from the stem length $l$ to the bending height $h_{\mathrm{v}}$. Thus, the effect means the stems of bending height $h_{\mathrm{v}}$ rather than that of the stem length $l$ resists the flowing water in a open channel. As a result, we call the parameter $A$ the effective bulk drag coefficient.

The no-slip condition at the channel bed gives

$$
u_{\mathrm{v}}\left(z_{0}\right)=0, \quad z_{0} \rightarrow 0
$$

where $z_{0}$ approaches zero under the condition of precision required, because Eq. (18) has no mathematical solution when $z=0$.

From the momentum balance of the flow above the vegetation, the interfacial shear stress between the vegetation and the free water layers gives another boundary condition ${ }^{[33]}$

$$
\tau\left(h_{\mathrm{v}}\right)=\left.\rho k_{\mathrm{v}} u_{*} h_{\mathrm{v}} \frac{\partial u_{\mathrm{v}}}{\partial z}\right|_{z=h_{\mathrm{v}}}=\rho u_{*}^{2} .
$$


Substituting Eq. (23) into Eq.(18) and Eq.(24) into Eq. (19), we obtain the integration coefficients

$$
\begin{aligned}
C_{1} & =\frac{\frac{2 u_{*}}{k_{\mathrm{v}} f\left(h_{\mathrm{v}}\right)} K_{0}\left(f\left(z_{0}\right)\right)-\frac{g i}{C_{\mathrm{v}} m D u_{*}} K_{1}\left(f\left(h_{\mathrm{v}}\right)\right)}{I_{0}\left(f\left(z_{0}\right)\right) K_{1}\left(f\left(h_{\mathrm{v}}\right)\right)+I_{1}\left(f\left(h_{\mathrm{v}}\right)\right) K_{0}\left(f\left(z_{0}\right)\right)}, \\
C_{2} & =\frac{C_{1} I_{1}\left(f\left(h_{\mathrm{v}}\right)\right)-\frac{2 u_{*}}{k_{\mathrm{v}} f\left(h_{\mathrm{v}}\right)}}{K_{1}\left(f\left(h_{\mathrm{v}}\right)\right)} .
\end{aligned}
$$

Substituting Eqs. (25) and (26) into Eq. (18) gives the velocity distribution in the vegetation layer.

2.2.2 Flow in free water layer

In the free water layer, there is no vegetation drag force. Therefore, the momentum equation can be expressed as

$$
\frac{\partial \tau}{\partial z}+\rho g i=0
$$

where the Reynolds stress in the non-vegetation layer can be expressed in the same way as for the vegetation layer

$$
\tau=\rho k_{\mathrm{n}} u_{*} z \frac{\partial u_{\mathrm{n}}}{\partial z}
$$

where $k_{\mathrm{n}}$ is the Kármán coefficient in the free water layer, and $u_{\mathrm{n}}$ is the flow velocity in the free water layer. Substituting Eq. (28) into Eq. (27) gives

$$
\frac{\partial}{\partial z}\left(k_{\mathrm{n}} u_{*} z \frac{\partial u_{\mathrm{n}}}{\partial z}\right)+g i=0 .
$$

The velocity in the free water layer can be obtained from

$$
u_{\mathrm{n}}(z)=-\frac{g i}{k_{\mathrm{n}} u_{*}} z+C_{3} \ln z+C_{4},
$$

where $C_{3}$ and $C_{4}$ are the integration coefficients, and the vertical gradient of the flow velocity is

$$
\frac{\partial u_{\mathrm{n}}}{\partial z}=-\frac{g i}{k_{\mathrm{n}} u_{*}}+\frac{C_{3}}{z}
$$

When the wind drag and surface tension at the water surface are ignored, the boundary condition can be expressed as

$$
\left.\frac{\partial u_{\mathrm{n}}}{\partial z}\right|_{z=H}=0 .
$$

Substituting Eq. (32) into Eq. (31) gives

$$
C_{3}=\frac{g i H}{k_{\mathrm{n}} u_{*}}
$$

The velocity distribution in the free water layer is obtained by substituting Eq. (33) into Eq. (30), i.e.,

$$
u_{\mathrm{n}}(z)=\frac{g i}{k_{\mathrm{n}} u_{*}}(H \ln z-z)+C_{4},
$$

where the integration coefficient $C_{4}$ can be obtained by another boundary condition

$$
u_{\mathrm{n}}\left(h_{\mathrm{v}}\right)=u_{\mathrm{v}}\left(h_{\mathrm{v}}\right) \text {. }
$$




\subsection{Determining coefficients}

The application of this analytical model requires the values of three parameters: the effective bulk drag coefficient $A$ and the two Kármán coefficients: $k_{\mathrm{v}}$ in the vegetation layer and $k_{\mathrm{n}}$ in the free water layer.

2.3.1 Effective bulk drag coefficient $A$

Measurements of Dunn et al. ${ }^{[34]}$ were adopted to determine the $A-I_{\mathrm{FA}}$ relationship by fitting the analytical model results to the measured velocity data, and a linear relationship was obtained (see Fig. 4) as follows:

$$
A=16.571 I_{\mathrm{FA}}
$$

Then, this equation was verified by the data of Kubrak et al. ${ }^{[30]}$, and we found that this linear $A-I_{\mathrm{FA}}$ was also suitable for the data of Kubrak et al. ${ }^{[30]}$, demonstrating the validity of this equation for determining the effective bulk drag coefficient. Equation (36) shows that the effective bulk drag coefficient $A=0$ when $I_{\mathrm{FA}}=0$, i.e., the vegetation resistance equals zero when vegetation does not exist, which is consistent with the actual situation.

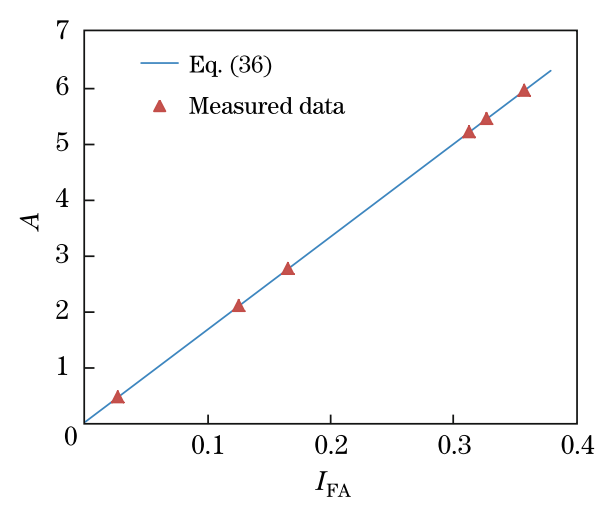

Fig. 4 Relationship between effective bulk drag coefficient and frontal area index

\subsubsection{Kármán coefficient $k_{\mathrm{v}}$}

Various methods have been used to express the Reynolds stress in the vegetation layer. Here, we present two approaches ${ }^{[33,35]}$.

In the first approach, Yang and Choi ${ }^{[3]}$ used the eddy viscosity

$$
\nu_{\mathrm{t}}=\frac{\kappa}{C_{\mathrm{u}}} u_{*} z
$$

with $C_{\mathrm{u}}=1$ for $m D \leqslant 5 \mathrm{~m}^{-1}$ and $C_{\mathrm{u}}=2$ for $m D \geqslant 5 \mathrm{~m}^{-1}$, and the Kármán constant $\kappa=0.41$. Then, the Reynolds stress can be expressed as

$$
\tau=\rho \nu_{\mathrm{t}} \frac{\partial u}{\partial z}=\rho\left(\frac{\kappa}{C_{\mathrm{u}}}\right) u_{*} z \frac{\partial u}{\partial z} .
$$

Compared with Eq. (14) adopted in this paper, $\kappa / C_{\mathrm{u}}$ of Yang and Choi ${ }^{[33]}$ can be seen as the Kármán coefficient $k_{\mathrm{v}}$, i.e.,

$$
k_{\mathrm{v}}=\frac{\kappa}{C_{\mathrm{u}}}
$$

In the second approach, Wang ${ }^{[35]}$ proposed an expression for the Reynolds stress based on a modified mixing length theory that takes into consideration the effects of both the ground and 
canopy elements on turbulent mixing in a wind profile, which is similar to that in flowing water

$$
\tau=\rho\left(\kappa s_{h}\right) u_{*} z \frac{\partial u}{\partial z}
$$

where the coefficient $s_{h}$ is calculated by

$$
s_{h}=\frac{l_{\mathrm{c}}}{\left(\left(l_{\mathrm{c}}\right)^{N}+\left(\kappa h_{\mathrm{v}}\right)^{N}\right)^{1 / N}},
$$

in which the subscript $h$ denotes the height of vegetation rods, and $N$ is a constant used to adjust the weights of the contributions of $\kappa h_{\mathrm{v}}$ and $l_{\mathrm{c}}$ to the mixing length. Here, $N=1$ is used for simplicity.

$$
l_{\mathrm{c}}=\frac{2\left(u_{*} / u\left(h_{\mathrm{v}}\right)\right)^{3}}{C_{\mathrm{d}} m D} .
$$

By comparing Eq. (40) with Eq. (14), the Kármán coefficient $k_{\mathrm{v}}$ can be expressed as

$$
k_{\mathrm{v}}=s_{h} \kappa .
$$

\subsubsection{Kármán coefficient $k_{\mathrm{n}}$}

There is no explicit theory to determine the Kármán coefficient $k_{\mathrm{n}}$ in the free water layer. Therefore, we determine this coefficient based on the experimental data ${ }^{[30,34]}$.

\section{Model verification} al. ${ }^{[30]}$.

Our analytical model is applied to the experimental data of Dunn et al. ${ }^{[34]}$ and Kubrak et

The experiments of Dunn et al. ${ }^{[34]}$ were conducted in a $19.5 \mathrm{~m}$ long, $0.91 \mathrm{~m}$ wide, and $0.61 \mathrm{~m}$ deep tilting flume, using plastic commercial drinking straws $(0.00635 \mathrm{~m}$ in diameter and $0.15875 \mathrm{~m}$ long) to simulate flexible vegetation.

Kubrak et al. ${ }^{[30]}$ conducted their experiments in a $16 \mathrm{~m}$ long and $0.58 \mathrm{~m}$ wide glass-walled flume. To simulate flexible vegetation, they used cylindrical stems of elliptical cross-section (the length of major axis $D_{1}=0.00095 \mathrm{~m}$, minor axis $D_{2}=0.0007 \mathrm{~m}$, and the stem height before bending is $0.165 \mathrm{~m}$ ). Different from the experimental data adopted by Huai et al. ${ }^{[9]}$, here we choose the large deflection cases from Kubrak et al. ${ }^{[30]}$ to verify the model proposed in this

\begin{tabular}{|c|c|c|c|c|c|c|}
\hline \multirow{2}{*}{ Data source } & \multicolumn{3}{|c|}{ Ref. [34] } & \multicolumn{3}{|c|}{ Ref. [30] } \\
\hline & Exp.13 & Exp.14 & Exp.16 & Run 3.1.1 & Run 3.2.1 & Run 4.2 .1 \\
\hline$i$ & 0.0036 & 0.0101 & 0.0036 & 0.0087 & 0.0174 & 0.0174 \\
\hline$A$ & 2.75 & 2.08 & 0.44 & 5.94 & 5.20 & 5.43 \\
\hline$k_{\mathrm{V}}$ & 0.17 & 0.14 & 0.33 & 0.14 & 0.12 & 0.15 \\
\hline$k_{\mathrm{n}}$ & 0.17 & 0.15 & 0.20 & 0.10 & 0.14 & 0.08 \\
\hline$D / \mathrm{m}$ & 0.00635 & 0.00635 & 0.00635 & 0.00095 & 0.00095 & 0.00095 \\
\hline$H / \mathrm{m}$ & 0.368 & 0.232 & 0.230 & 0.2386 & 0.1962 & 0.2077 \\
\hline$h_{\mathrm{v}} / \mathrm{m}$ & 0.152 & 0.115 & 0.097 & 0.151 & 0.132 & 0.138 \\
\hline$m\left(\right.$ stems $\left./ \mathrm{m}^{2}\right)$ & 171.7 & 171.7 & 43.0 & 2500 & 2500 & 2500 \\
\hline Averaged bending angle $/\left(^{\circ}\right)$ & 35 & 51 & 65 & 30 & 40 & 44 \\
\hline
\end{tabular}
paper.

The parameters of the experiments are given in Table 1.

Table 1 Experimental parameters 
The effective bulk drag coefficient $A$ shown in Table 1 is calculated using Eq. (36). The Kármán coefficients $k_{\mathrm{v}}$ and $k_{\mathrm{n}}$ are determined by fitting the analytical model results to experimental data. The averaged bending angles are also taken from the experimental data.

Table 2 compares the Kármán coefficients obtained by the different approaches mentioned above. In the vegetation layer, $k_{\mathrm{v}}$ is determined based on the fitting experimental data, and $k_{\mathrm{v} 1}$ was obtained by Yang and Choi ${ }^{[33]} . \quad k_{\mathrm{v} 2}$ was obtained by Wang ${ }^{[35]}$, in which the drag coefficient $C_{\mathrm{d}}=1.13$ by Dunn ${ }^{[36]}$ was used in Eq. (42). This value of $C_{\mathrm{d}}$ matches the analytical estimates of $\mathrm{Li}$ and Shen ${ }^{[37]}$ and has been widely used by many other researchers ${ }^{[33,38-40]} . k_{\mathrm{v} 3}$ was obtained by Kubrak et al. ${ }^{[30]}$ using numerical methods. For the Kármán coefficient in the free water layer, $k_{\mathrm{n}}$ denotes the value fitting the experimental data, and $k_{\mathrm{n} 1}$ was the result obtained by Kubrak et al. ${ }^{[30]}$.

Table 2 Comparison of Kármán coefficients by different methods

\begin{tabular}{cccccccc}
\hline \multirow{2}{*}{ Data source } & \multicolumn{3}{c}{ Ref. [34] } & & \multicolumn{3}{c}{ Ref. [30] } \\
\cline { 2 - 4 } \cline { 6 - 8 } & Exp.13 & Exp.14 & Exp.16 & & Run 3.1.1 & Run 3.2.1 & Run 4.2.1 \\
\hline$k_{\mathrm{v}}$ & 0.170 & 0.140 & 0.330 & & 0.140 & 0.120 & 0.150 \\
$k_{\mathrm{v} 1}$ & 0.410 & 0.410 & 0.410 & & 0.410 & 0.410 & 0.410 \\
$k_{\mathrm{v} 2}$ & 0.052 & 0.016 & 0.033 & & 0.030 & 0.013 & 0.027 \\
$k_{\mathrm{v} 3}$ & - & - & - & & 0.105 & 0.115 & 0.130 \\
$k_{\mathrm{n}}$ & 0.170 & 0.150 & 0.200 & & 0.100 & 0.140 & 0.080 \\
$k_{\mathrm{n} 1}$ & - & - & - & & 0.110 & 0.095 & 0.090 \\
\hline
\end{tabular}

Figure 5 compares the measured velocity with the predicted velocity of this analytical model. The theoretical results are in good agreement with the experimental data, demonstrating that the theoretical formula can be used to predict the streamwise velocity distribution of flow through large bending flexible vegetation.
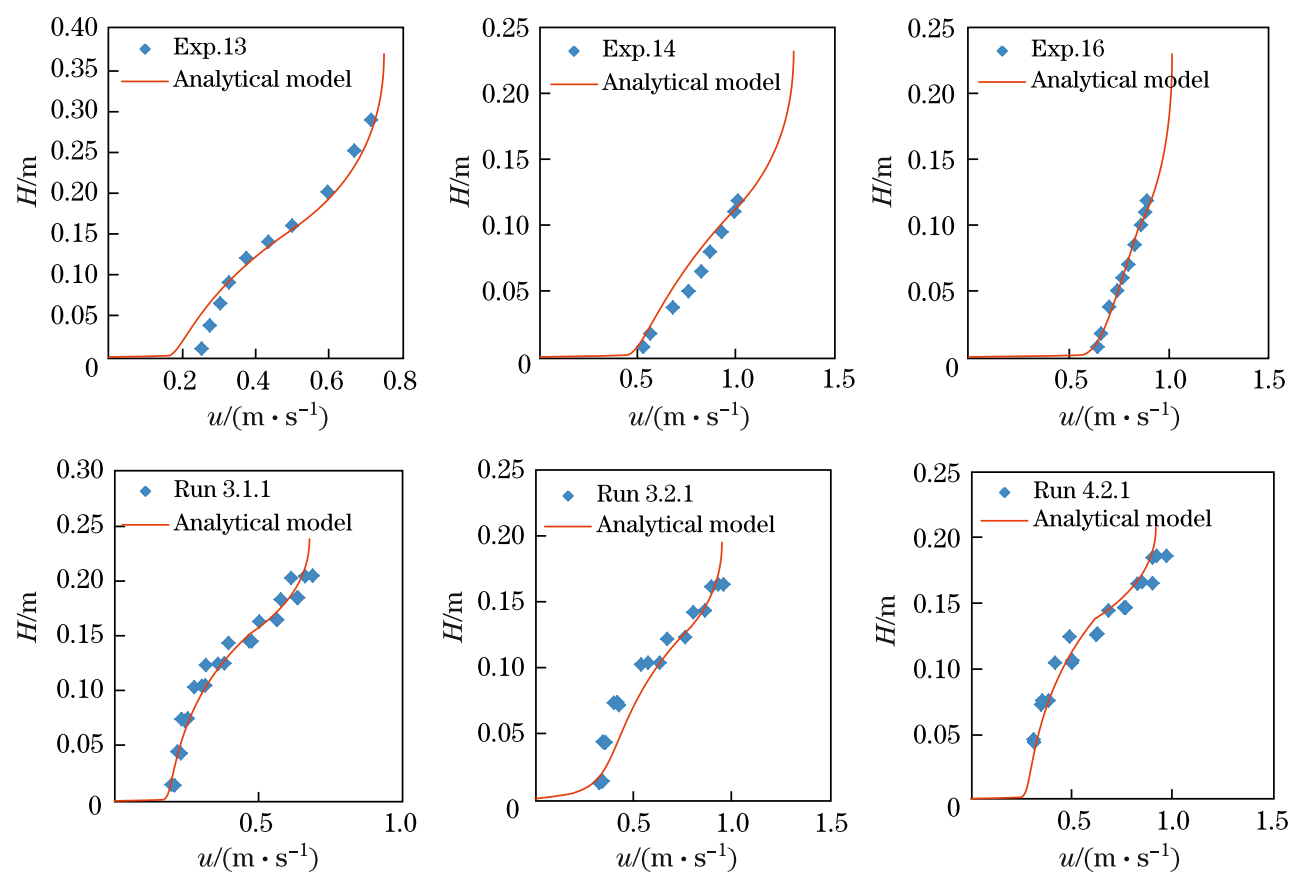

Fig. 5 Comparison of measurements and analytical results 


\section{Discussion}

In Table 2, we see that $k_{\mathrm{v} 1}$ and $k_{\mathrm{v} 2}$ are deviated from $k_{\mathrm{v}}$, suggesting that these two approaches ${ }^{[33,35]}$ are not suitable for the experimental data used here. However, the values of the Kármán coefficients in Ref. [30] for the whole flow region are close to those obtained using our analytical model even though different models were used, i.e., $k_{\mathrm{v} 3}$ and $k_{\mathrm{n} 1}$ are close to $k_{\mathrm{v}}$ and $k_{\mathrm{n}}$, respectively. Moreover, the values of the Kármán coefficients in these five cases are different from that of Kármán constant $\kappa=0.41$, because the Kármán coefficients obtained here are affected by many factors such as the vegetation density, the bed slope, the water depth, the shear velocity, and the velocity at the top of vegetation ${ }^{[33,35]}$, which results in difficulty of determining the Kármán coefficients.

Due to the difficulty of determining the Kármán coefficient in explicit formulas, the effective bulk drag coefficient $A$ (Eq. (21) embeds the Kármán coefficient $k_{\mathrm{v}}$ ) here is calculated by Eq. (36), which is determined by the data of Dunn et al. ${ }^{[34]}$ and verified by the data of Kubrak et al. ${ }^{[30]}$. The results show that this equation is applicable to the cases adopted in this paper. Although this equation proves effective in the model verification, one should notice that this $A$ $I_{\mathrm{FA}}$ relationship may be different for other situations owing to limited cases to obtain Eq. (36). A more effective approach is needed to investigate the effective bulk drag coefficient in future investigation.

Figure 5 shows that our analytical model is applicable for flexible vegetation in an open channel flow in the case of large deflection. Based on the data adopted in the model verification, in which the minimum averaged bending angle (Run 3.1.1) is $30^{\circ}$, the large deflection in this paper indicates that the averaged bending angle is larger than $30^{\circ}$.

\section{Conclusions}

An analytical model of vertical distribution which is suitable for the open channel flow with large bending flexible vegetation is established. This model is convenient in predicting the velocity distribution compared with numerical solutions and field investigations. We present a new linear drag force-velocity relationship, which is a new attempt to describe the vegetation drag when significant bending occurs. This is consistent with observations by other researchers in recent years. The velocity distribution for each layer is presented, and the good agreement between the model results and previous data demonstrates that this linear streamwise drag force-mean velocity is effective for the open channel vegetated flow when the averaged bending angle is larger than $30^{\circ}$. Although this trial is proved to be successful, further detailed studies are required to provide more effective approaches for determining the Kármán coefficients and the effective bulk drag coefficient.

\section{References}

[1] Nepf, H. and Ghisalberti, M. Flow and transport in channels with submerged vegetation. Acta Geophysica, 56(3), 753-777 (2008)

[2] Baptist, M., Babovic, V., Rodríguez-Uthurburu, J., Keijzer, M., Uittenbogaard, R. E., Mynett, A., and Verwey, A. On inducing equations for vegetation resistance. Journal of Hydraulic Research, 45(4), 435-450 (2007)

[3] Stephan, U. and Gutknecht, D. Hydraulic resistance of submerged flexible vegetation. Journal of Hydrology, 269(1), 27-43 (2002)

[4] Abdelrhman, M. A. Modeling coupling between eelgrass Zostera marina and water flow. Marine Ecology Progress Series, 338(24), 81-96 (2007)

[5] Wilson, C., Stoesser, T., Bates, P., and Pinzen, A. B. Open channel flow through different forms of submerged flexible vegetation. Journal of Hydraulic Engineering, 129(11), 847-853 (2003) 
[6] Ghisalberti, M. and Nepf, H. The structure of the shear layer in flows over rigid and flexible canopies. Environmental Fluid Mechanics, 6(3), 277-301 (2006)

[7] Chen, L., Stone, M. C., Acharya, K., and Steinhaus, K. A. Mechanical analysis for emergent vegetation in flowing fluids. Journal of Hydraulic Research, 49(6), 766-774 (2011)

[8] Luhar, M. and Nepf, H. M. Flow-induced reconfiguration of buoyant and flexible aquatic vegetation. Limnology and Oceanography, 56(6), 2003-2017 (2011)

[9] Huai, W. X., Wang, W. J., and Zeng, Y. H. Two-layer model for open channel flow with submerged flexible vegetation. Journal of Hydraulic Research, 51(6), 708-718 (2013)

[10] Hoerner, S. F. Fluid Dynamic Drag, Published by the author, Bricktown (1965)

[11] Kouwen, N. and Fathi-Moghadam, M. Friction factors for coniferous trees along rivers. Journal of Hydraulic Engineering, 126(10), 732-740 (2000)

[12] Vogel, S. Life in Moving Fluids: The Physical Biology of Flow, Princeton University Press, Princeton (1981)

[13] Gosselin, F., de Langre, E., and MacHado-Almeida, B. A. Drag reduction of flexible plates by reconfiguration. Journal of Fluid Mechanics, 650, 319-341 (2010)

[14] Vogel, S. Drag and reconfiguration of broad leaves in high winds. Journal of Experimental Botany, 40(8), 941-948 (1989)

[15] De Langre, E., Gutierrez, A., and Cossé, J. On the scaling of drag reduction by reconfiguration in plants. Comptes Rendus Mecanique, 340(1), 35-40 (2012)

[16] Armanini, A., Righetti, M., and Grisenti, P. Direct measurement of vegetation resistance in prototype scale. Journal of Hydraulic Research, 43(5), 481-487 (2005)

[17] Wilson, C., Xavier, P., Schoneboom, T., Aberle, J., Rauch, H., Lammeranner, W., Weissteiner, C., and Thomas, H. The hydrodynamic drag of full scale trees. Fluvial Hydraulics River Flow 2010 (eds. Dittrich, A., Koll, K., Aberle, J., and Geisenhainer, P.), Bundesanstalt für Wasserbau, Karlsruhe, 453-459 (2010)

[18] Schoneboom, T., Aberle, J., and Dittrich, A. Hydraulic resistance of vegetated flows: contribution of bed shear stress and vegetative drag to total hydraulic resistance. Fluvial Hydraulics River Flow 2010 (eds. Dittrich, A., Koll, K., Aberle, J., and Geisenhainer, P.), Bundesanstalt für Wasserbau, Karlsruhe, 269-276 (2010)

[19] Järvelä, J. Flow resistance of flexible and stiff vegetation: a flume study with natural plants. Journal of Hydrology, 269(1), 44-54 (2002)

[20] Wilson, C. Flow resistance models for flexible submerged vegetation. Journal of Hydrology, 342(3), 213-222 (2007)

[21] Carollo, F. G., Ferro, V., and Termini, D. Flow resistance law in channels with flexible submerged vegetation. Journal of Hydraulic Engineering, 131(7), 554-564 (2005)

[22] Wang, L. L. Large eddy simulation theory and its application. Journal of Hohai University (Natural Sciences), 32(3), 261-265 (2004)

[23] Klopstra, D., Barneveld, H., van Noortwijk, J., and van Velzen, E. Analytical model for hydraulic roughness of submerged vegetation. 27th Congress of the International Association for Hydraulic Research, American Society of Civil Engineers, New York, 775-780 (2002)

[24] Huai, W. X., Chen, Z. B., Han, J., Zhang, L. X., and Zeng, Y. H. Mathematical model for the flow with submerged and emerged rigid vegetation. Journal of Hydrodynamics, Ser. B, 21(5), 722-729 (2009)

[25] Huai, W. X., Zeng, Y. H., Xu, Z. G., and Yang, Z. H. Three-layer model for vertical velocity distribution in open channel flow with submerged rigid vegetation. Advances in Water Resources, 32(4), 487-492 (2009)

[26] Liu, Z. W., Chen, Y. C., Zhu, D. J., Hui, E. Q., and Jiang, C. B. Analytical model for vertical velocity profiles in flows with submerged shrub-like vegetation. Environmental Fluid Mechanics, 12(4), 341-346 (2012)

[27] Yang, K. J., Liu, X. N., Cao, S. Y., Shi, B., and Zhang, Z. X. Velocity distribution in compound channels with vegetated floodplains. Chinese Journal of Hydraulic Engineering, 38(2), 246-250 (2006) 
[28] Zhang, M. L., Shen, Y. M., and Zhu, L. Y. Depth-averaged two-dimensional numerical simulation for curved open channels with vegetation. Journal of Hydraulic Engineering, 39(7), 794-800 (2008)

[29] Bootle, W. Forces on an inclined circular cylinder in supercritical flow. AIAA Journal, 9(3), 514-516 (1971)

[30] Kubrak, E., Kubrak, J., and Rowinski, P. M. Vertical velocity distributions through and above submerged, flexible vegetation. Hydrological Sciences Journal, 53(4), 905-920 (2008)

[31] Schlichting, H. Boundary Layer Theory, McGraw-Hill, New York (1979)

[32] Oertel, H. Fundamental Equations of Fluid Mechanics, Springer, New York (2010)

[33] Yang, W. and Choi, S. U. A two-layer approach for depth-limited open-channel flows with submerged vegetation. Journal of Hydraulic Research, 48(4), 466-475 (2010)

[34] Dunn, C. J., López, F., and García, M. H. Mean flow and turbulence in a laboratory channel with simulated vegetation. Hydraulic Engineering Series No.51, UILU-ENG-96-2009, Hydrosystems laboratory, Department of Civil Engineering, University of Illinois at Urbana-Champaign, Champaign (1996)

[35] Wang, W. G. An analytical model for mean wind profiles in sparse canopies. Boundary-Layer Meteorology, 142(3), 383-399 (2012)

[36] Dunn, C. Experimental Determination of Drag Coefficients in Open Channel with Simulated Vegetation, M. Sc. dissertation, University of Illinois (1996)

[37] Li, R. M. and Shen, H. W. Effect of tall vegetations on flow and sediment. Journal of the Hydraulics Division, 99(5), 793-814 (1973)

[38] Yang, W. and Choi, S. U. Impact of stem flexibility on mean flow and turbulence structure in depth-limited open channel flows with submerged vegetation. Journal of Hydraulic Research, 47(4), 445-454 (2009)

[39] López, F. and García, M. H. Mean flow and turbulence structure of open-channel flow through non-emergent vegetation. Journal of Hydraulic Engineering, 127(5), 392-402 (2001)

[40] Konings, A. G., Katul, G. G., and Thompson, S. E. A phenomenological model for the flow resistance over submerged vegetation. Water Resources Research, 48(2) (2012) DOI10.1029/ 2011WRD11000 